Article

\title{
Antimony Mining from PET Bottles and E-Waste Plastic Fractions
}

\author{
Ayah Alassali ${ }^{1, *(\mathbb{D}}$, Caterina Picuno ${ }^{1}$, Hanin Samara ${ }^{2}{ }^{\mathbb{D}}$, Sascha Diedler ${ }^{1}$, Silvia Fiore $^{3} \mathbb{D}$ and \\ Kerstin Kuchta ${ }^{1}$ \\ 1 Institute of Environmental Technology and Energy Economics, Waste Resources Management, \\ TUHH—Hamburg University of Technology, Harburger Schloßstr, 36, 21079 Hamburg, Germany \\ 2 Department of Mechanical Engineering, University of Jordan, Queen Rania St., Amman 11942, Jordan \\ 3 DIATI (Department of Environment, Land and Infrastructure Engineering), Politecnico di Torino, corso Duca \\ degli Abruzzi 24, 10129 Turin, Italy \\ * Correspondence: ayah.alassali@tuhh.de
}

Received: 26 June 2019; Accepted: 22 July 2019; Published: 25 July 2019

check for updates

\begin{abstract}
In this study antimony concentration was analyzed in 30 plastic items (from polyethylene terephthalate (PET) bottles and e-waste) directly by X-ray fluorescence spectroscopy (XRF) spectroscopy. PET samples were digested in a microwave oven with aqua regia. The plastic components deriving from e-waste followed three parallel routes: 1 . microwave digestion using different acids (aqua regia, $18 \mathrm{M} \mathrm{H}_{2} \mathrm{SO}_{4}, 12 \mathrm{M} \mathrm{HCl}$ and $6 \mathrm{M} \mathrm{HCl}$ ); 2. conversion into ash (at $600{ }^{\circ} \mathrm{C}$ ) and then microwave digestion with aqua regia, and 3. extraction with $12 \mathrm{M} \mathrm{HCl}$ at room temperature for different durations ( $2 \mathrm{~h}$ and $24 \mathrm{~h}$ ). Results showed that antimony extraction yields from PET were between $57 \%$ and $92 \%$. Antimony extraction from e-waste plastics was more challenging: aqua regia was inefficient for poly (acrylonitrile butadiene styrene) (ABS) samples (extraction yield was about $20 \%$ only), while on a mixture of $\mathrm{ABS}$ and polycarbonate (PC), aqua regia, $\mathrm{H}_{2} \mathrm{SO}_{4}$ and $\mathrm{HCl}$ exhibited equivalent performances ( $21 \%$ ). Ashed samples returned yields ranging from $20 \%$ to over $50 \%$. Room temperature extraction on e-waste plastics obtained lower extraction efficiencies, yet longer incubation durations lead to higher yields. In conclusion, the main challenge associated with antimony mining from plastic waste could be its heterogeneous composition; therefore, the development of reference analytical procedures is highly needed.
\end{abstract}

Keywords: antimony; e-waste; extraction; PET; plastic; recovery

\section{Introduction}

In recent years, antimony $(\mathrm{Sb})$ has increasingly become a critically exhaustible resource. Although it was originally classified as a scarce resource with a low concentration in the earth's crust, the amount of $\mathrm{Sb}$ in the environment has been increasing due to excessive mining activities, burning of fossil fuels and industrial production of commodities such as textiles, plastics, electronics, ceramics, glass decolorizers, lead batteries and flame retardants [1]. Antimony was identified by the European Commission (EC) as a critical raw material (CRM), on which Europe's economy is highly dependent [2]. China is currently dominating the global production of $\mathrm{Sb}$; in 2015 it accounted for about $77 \%$ of the world's total production [3]. This in turn results in EU's dependence on China for the supply of $\mathrm{Sb}$, and consequently stirs concerns regarding the disruption of its secure and sustainable supply. It is expected that $\mathrm{Sb}$ will reach its highest "supply and demand deficit" over the period 2015-2020 [2]. Extractable global reserve of $\mathrm{Sb}$ was estimated in 2008 by the United States Geological Survey (USGS) to be around 2.1 million tons [4], while in 2016 it decreased to about 1.5 million tons [5]; this shows about a $30 \%$ reduction in the global recoverable reserve in less than a decade and in turn asserts the rapid exhaustibility of $\mathrm{Sb}$. 
Consequently, it has become crucial to improve the consumption efficiency of such a resource and to effectively identify the conditions for its recyclability. Accordingly, and in line with its circular economy action plan (COM/2015/0614), the EC has mandated recycling to reduce the risk of insufficient supply of $\mathrm{Sb}$ and other CRMs [2]. The end-of-life recycling input rate (EOL-RIR)-defined as the ratio of the amount of CRM recovered from recycling to the total amount of material's input into production-of $\mathrm{Sb}$ in the EU is estimated to be around 28\% (see Figure 1) [6]. The low EOL-RIR can be attributed to many factors, such as the absence of sorting and recycling technologies at competitive costs and the retention of $\mathrm{Sb}$ in many long-life assets such as lead alloys that are used in construction. Additionally, the EOL-RIR is highly affected by in-use dissipation, which results in a reduction in materials availability for recovery and reuse, greater dependence on primary geological resources, in addition to increased settling of $\mathrm{Sb}$ in various ecosystems $[7,8]$. Heckens et al. (2016) proposed an extraction rate reduction of $94 \%$ from those of the year 2010 through efficient $\mathrm{Sb}$ use, increased recycling and finding suitable substitutes of such resource in applications where it is used [9].

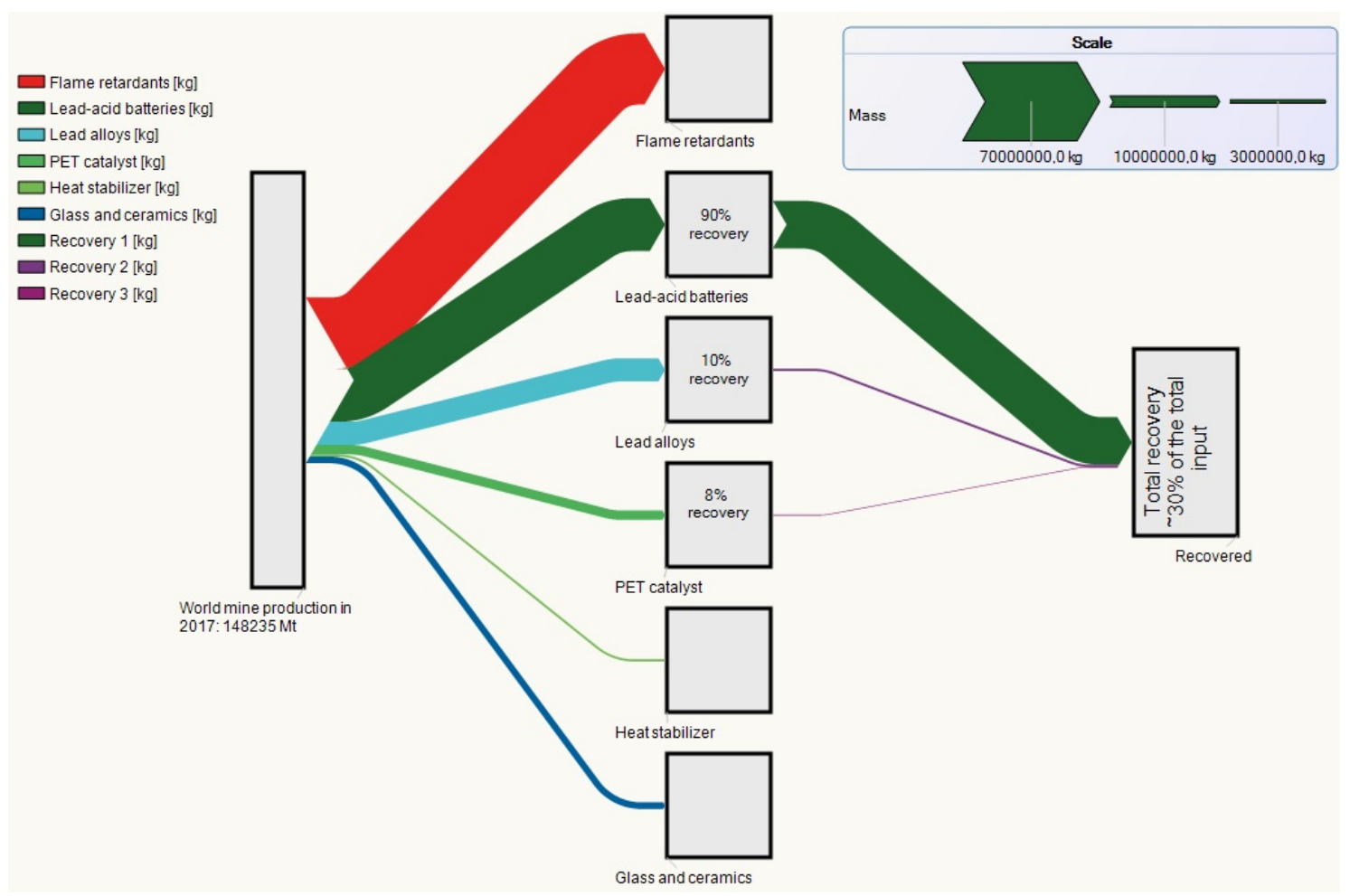

Figure 1. An overview of antimony (Sb) utilization in different industrial applications [9-11].

The global consumption of $\mathrm{Sb}$ in 2018 was estimated as follows [11] (Figure 1): 43\% in flame retardants, $46 \%$ in lead batteries and lead alloys, $6 \%$ in catalysts for the production of polyethylene terephthalate (PET) bottles, and 5\% for chemicals, glass and ceramics. However, and as a consequence of the dissipative distribution of $\mathrm{Sb}$, no recycling processes exist on a technical scale for most fields of application [12], except for lead-acid batteries [9]. As a consequence, the global functional recycling rate of non-metallurgical applications at present ranges from $1 \%$ to $10 \%[13,14]$, indicating an ineffective recovery. It was reported that secondary $\mathrm{Sb}$ sources (e.g., fly ashes, slags from lead refineries and scraps), industrial by-products (e.g., dump material, waste from metals extraction) and other activities (e.g., landfills or residues from waste incineration) are of increasing interest for its recovery [12].

Antimony is present in many plastic materials, mostly as synergetic flame-retardant, and for this reason it is found within the waste cycle [15]. A recent study revealed the ubiquity of $\mathrm{Sb}$ in plastics used in various applications [16]. In another study [17], different types of acids were tested to assess their efficiency in leaching $\mathrm{Sb}$ from a discarded computer housing, made of poly (acrylonitrile butadiene 
styrene) (ABS). Results showed that the leaching medium (i.e., heated solution of sodium hydrogen tartrate in dimethyl sulfoxide) could leach up to $50 \%$ of the $\mathrm{Sb}$ from ABS.

On one hand, numerous efforts have been done to assess the concentration of $\mathrm{Sb}$ in plastics (e.g., [16]), on the other, very few studies regarding Sb extraction from different polymers for the aim of recycling are available $[17,18]$. Moreover, reference analytical procedures are completely missing. This work was focused on plastic components of e-waste, containing relevant amounts of Sb [19], and on PET bottles, chosen because of their high abundance in plastic waste flows [20] and significant $\mathrm{Sb}$ content (up to $200-350 \mathrm{mg} / \mathrm{kg}$ ) [21-23]. E-waste management should be heavily improved to achieve EU targets [24] and to limit its environmental impacts [25]. Furthermore, in 2007, 24\% of PET were globally recycled; $72 \%$ of recycled PET flakes were utilized in polyester fiber and $10 \%$ reused in bottles [26]. Meaning that, from both plastic waste flows, the recycled material will potentially mobilize $\mathrm{Sb}$ into different production cycles as well as into the environment. Therefore, easy and economical methodologies of extraction need to be investigated for $\mathrm{Sb}$ mining from plastic waste.

With these premises, this research aims at giving an assessment of $\mathrm{Sb}$ recovery through acid extraction from e-waste plastic fraction and PET bottles. This would, on the one hand, fill the knowledge gaps in the current literature on $\mathrm{Sb}$ extraction from different polymers and, on the other hand, provide a first basis for further developing the extraction methodology eventually leading to the development of large-scale application. Firstly, the different polymers were identified, and the Sb content was directly measured in all samples ( 30 items) through X-ray fluorescence spectroscopy (XRF). Afterwards, different types (aqua regia, hydrochloric and sulfuric acids) and concentrations of acids have been investigated as leaching agents, in addition to microwave-assisted extraction. Plastics derived from e-waste underwent microwave-assisted acidic extraction, both unaltered and after their conversion to ashes at $600^{\circ} \mathrm{C}$. Plastics from e-waste also underwent room-temperature acidic extraction, to evaluate the extraction yield towards $\mathrm{Sb}$, as well as the effects on the plastic items. This work had two objectives: 1. to investigate $\mathrm{Sb}$ recovery from waste plastics and their ashes, thus hypothesizing different waste management routes (separate collection of PET and of plastics from e-waste); 2 . to evaluate the possibility to convert plastic waste into a non-hazardous fraction, which can be easily returned into the production cycle after $\mathrm{Sb}$ extraction, or disposed without further treatment.

\section{Materials and Methods}

\subsection{Samples Origin}

Two materials were considered in this study: PET from bottles and mixed plastics from e-waste, due to the presence of $\mathrm{Sb}$ in these two waste streams [19,21]. Virgin PET granules from NEOPET 82 FR-INEOS Olefins and Polymers Europe were considered as reference material. PET samples (about $300 \mathrm{~g}$ each) had three different origins:

- $\quad$ washed and shredded PET flakes, prepared for recycling (provided from a bottle-to-bottle recycling facility in Germany),

- PET from recyclable soft-drink bottles,

- $\quad$ PET from water bottles.

As for the plastic fraction from e-waste, the samples were obtained from an e-waste collection point in Hamburg (Germany). The analyzed items were 27 in total: external hard plastic casings of 20 mobile phones, external casings of five laptops, an external casing of one PC screen, and an external casing of one TV screen.

\subsection{Samples Preparation}

PET samples from soft-drinks and water bottles were cut with scissors into pieces (size smaller than $5.0 \mathrm{~mm} \times 5.0 \mathrm{~mm}$ ). E-waste plastic parts were manually dismantled and qualitatively analyzed by near infrared (NIR) spectroscopy using a Thermo Fisher Scientific ${ }^{\mathrm{TM}}$ microPHAZIR ${ }^{\mathrm{TM}}$ RX Analyzer. 
Each of the identified polymers was singly shredded to a particle size $\leq 4.0 \mathrm{~mm}$ in two steps, first using a JBF universal shredding machine, secondly, through a SM 300 Retsch Cutting Mill.

\subsection{Total Antimony Concentration Assessment}

The total $\mathrm{Sb}$ concentration in the considered samples was measured using XRF (Thermo Fisher Scientific $^{\mathrm{TM}}$ Niton $^{\mathrm{TM}}$ XL3t XRF-Analyzer, MA, USA. The normal filter was applied to analyze $\mathrm{Sb}$ in the 'plastics mode', based on characteristic peak at $26.359 \mathrm{KeV}(\mathrm{K} \alpha)$. The XRF was used in a collapsible bench-top accessory stand (Thermo Scientific SmartStand), with a stainless-steel window-surrounding base and directly connected to a computer via USB. Analyses were done in triplicates. A Multi-element Reference Sample EN 71-3, LOT \# T-60 was analyzed as a reference sample for cross-validation.

\subsection{PET Samples Acidic Extraction}

An acidic extraction according to DIN EN 16174 procedure was performed (0.5-1.0 g sample was digested in $10 \mathrm{~mL}$ of aqua regia) by a CEM Mars 6 microwave oven $\left(175^{\circ} \mathrm{C}\right.$ for $15 \mathrm{~min}$ at $\left.800 \mathrm{psi}\right)$. Acidic extracts were filtered on $1.2 \mu \mathrm{m}$ membranes and diluted to $100 \mathrm{~mL}$ with deionized water.

\subsection{E-Waste Plastics}

In order to assess the $\mathrm{Sb}$ content in e-waste plastics, the samples were analyzed in their original form and as ashes (see Figure 2), hypothesizing that e-waste plastics could be both separately collected for recycling or incinerated.

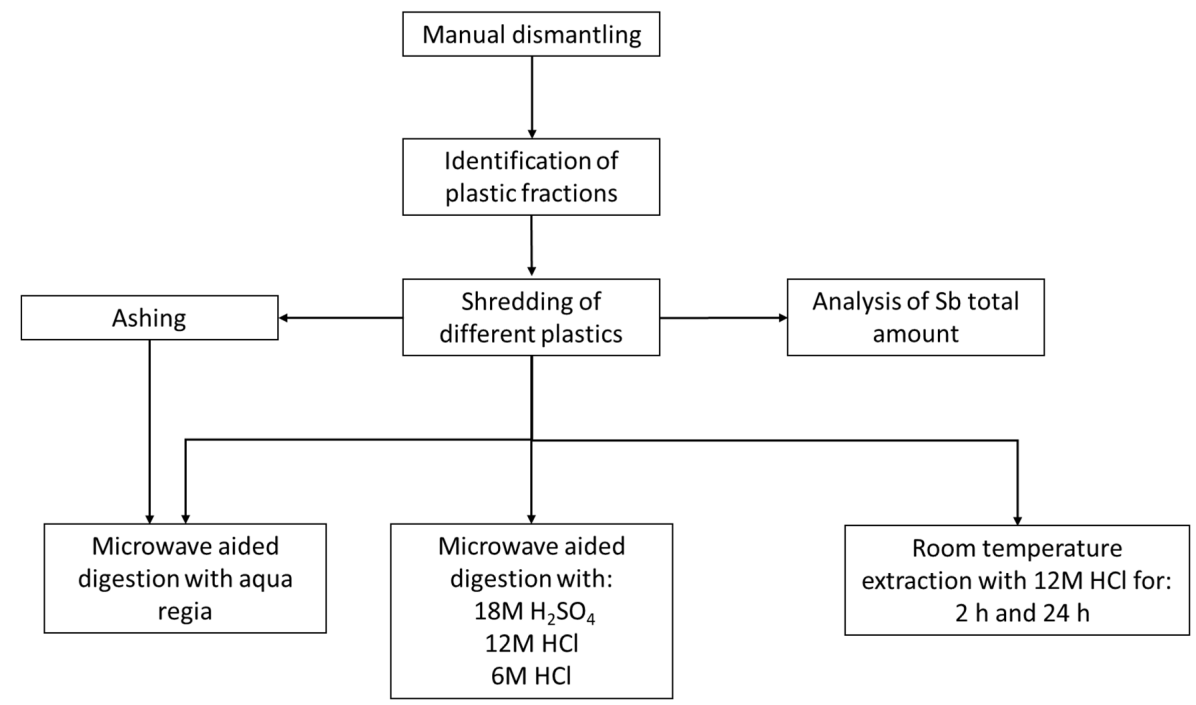

Figure 2. Experimental procedure implemented on e-waste plastic samples.

\subsubsection{Ashing}

The ISO standard 3451-1 procedure A [27] was followed to evaluate the ash content in samples obtained from e-waste plastic specimens. The samples were weighed and placed inside porcelain crucibles, then pre-burned with a butane Bunsen burner. Afterwards the samples were converted into ashes in a muffle at $600^{\circ} \mathrm{C}$. The samples were taken out from the muffle every half hour, cooled in a desiccator and weighed. This step was repeated until a constant mass was obtained (total time not exceeding $3 \mathrm{~h}$ ) [28].

\subsubsection{Acidic Extraction}

Preliminary tests performed on e-waste plastic components proved aqua regia as an ineffective acidic extraction medium [28]. Therefore, with the aim of investigating other leaching phases, e-waste plastic samples were microwave-digested using different acids: $6 \mathrm{M} \mathrm{HCl}, 12 \mathrm{M} \mathrm{HCl}$ and $18 \mathrm{M} \mathrm{H}_{2} \mathrm{SO}_{4}$, 
adopting the conditions detailed in Section 2.4. Ashed samples (0.5-1.0 g) were also microwave-digested in duplicates adopting the same conditions detailed in Section 2.4.

To compare the results obtained by applying microwave extraction to less expensive and less harsh methods, a milder extraction was tested solely on e-waste plastic samples. Triplicates of $0.5-1.0 \mathrm{~g}$ samples were soaked in $10 \mathrm{~mL}$ of $12 \mathrm{M} \mathrm{HCl}$ at $20^{\circ} \mathrm{C}$. In order to assess the degree of influence of the digestion time, two incubation durations were chosen; $2 \mathrm{~h}$ and $24 \mathrm{~h}$. At this point, it is worth mentioning that $\mathrm{Sb}_{2} \mathrm{O}_{3}$ is not very soluble, and non-oxidizing acids are not able to react with $\mathrm{Sb}$ unless $\mathrm{O}_{2}$ is present [29]. The use of $\mathrm{HCl}$ was hypothesized since $\mathrm{HCl}$ is used extensively in industrial applications [30] and analysis of environmental samples [31,32].

\subsection{Antimony Analysis After Acidic Extraction}

The acidic solutions obtained from the different extraction trials were vacuum-filtered through glass fiber with a pore size of $1.2 \mu \mathrm{m}$, and then diluted to $100 \mathrm{~mL}$ with distilled water. The analysis of $\mathrm{Sb}$ concentration was performed through an Agilent 5100 inductively coupled plasma atomic emission spectroscopy (ICP-OES), after a calibration with ICP-OES multi-element calibration standard-3 from Agilent (part number 8500-6948).

\section{Results}

\subsection{Antimony Recovery from PET}

The direct assessment of $\mathrm{Sb}$ concentration in PET samples revealed a total content ranging between 231.3 and $256.8 \mathrm{mg} / \mathrm{kg}$. As shown in Figure 3, $71.4 \pm 6.3 \%$ of the total $\mathrm{Sb}$ could be extracted from virgin PET, PET from the water bottles achieved the highest yield $(92.5 \pm 16.4 \%)$, and PET from soft drinks bottles showed a wide variation in the extraction yield (78.3 $\pm 47.4 \%)$. PET flakes originating from the recycling facility exhibited the lowest yield with a significant variation $(56.6 \pm 33.6 \%)$.

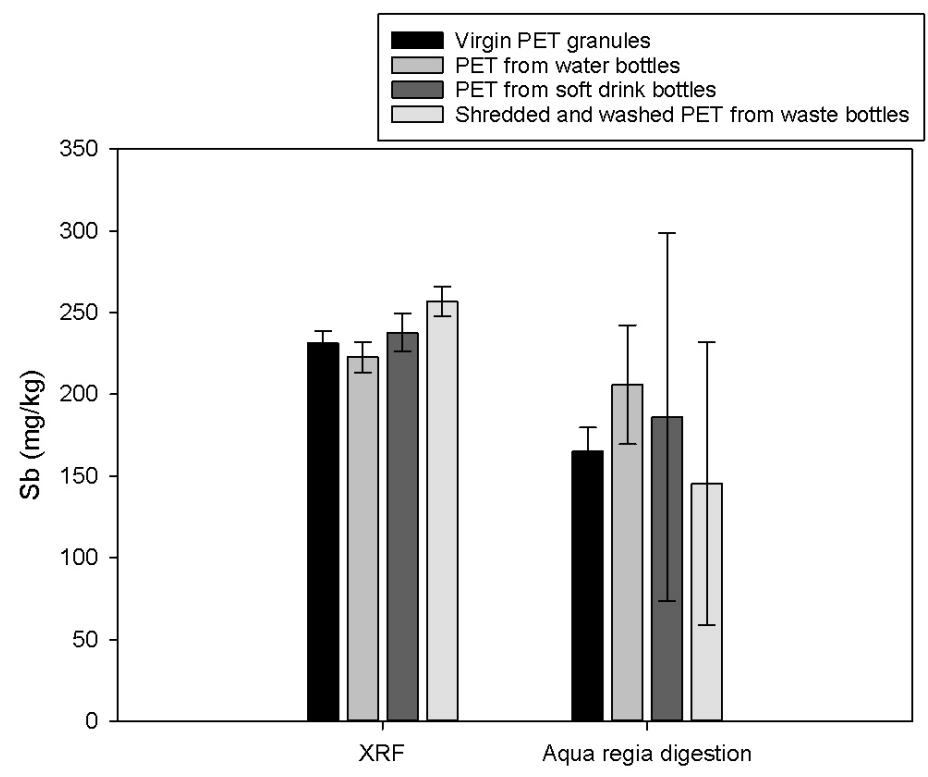

Figure 3. Antimony concentration in PET samples: direct measurement through XRF and microwave assisted digestion with aqua regia and ICP-EOS analysis of the extract.

\subsection{Antimony Recovery from E-Waste Plastics}

\subsubsection{Antimony Total Amount in Shredded Samples}

The XRF analysis (Figure 4) indicated minor concentrations of $\mathrm{Sb}$ in the mobile phone external covers $(25.4 \pm 15.3 \mathrm{mg} / \mathrm{kg})$, with a relevant variability among items of different models and brands. 
The same trend was observed in the PC screen (Sb concentration $21.7 \pm 11.7 \mathrm{mg} / \mathrm{kg}$ ). On the other hand, $\mathrm{Sb}$ was absent in the TV screen plastic fraction (concentrations below the detection limits $14 \mathrm{ppm}$ ). An elevated $\mathrm{Sb}$ concentration was detected in laptop casings $(152.5 \pm 64.9 \mathrm{mg} / \mathrm{kg})$.

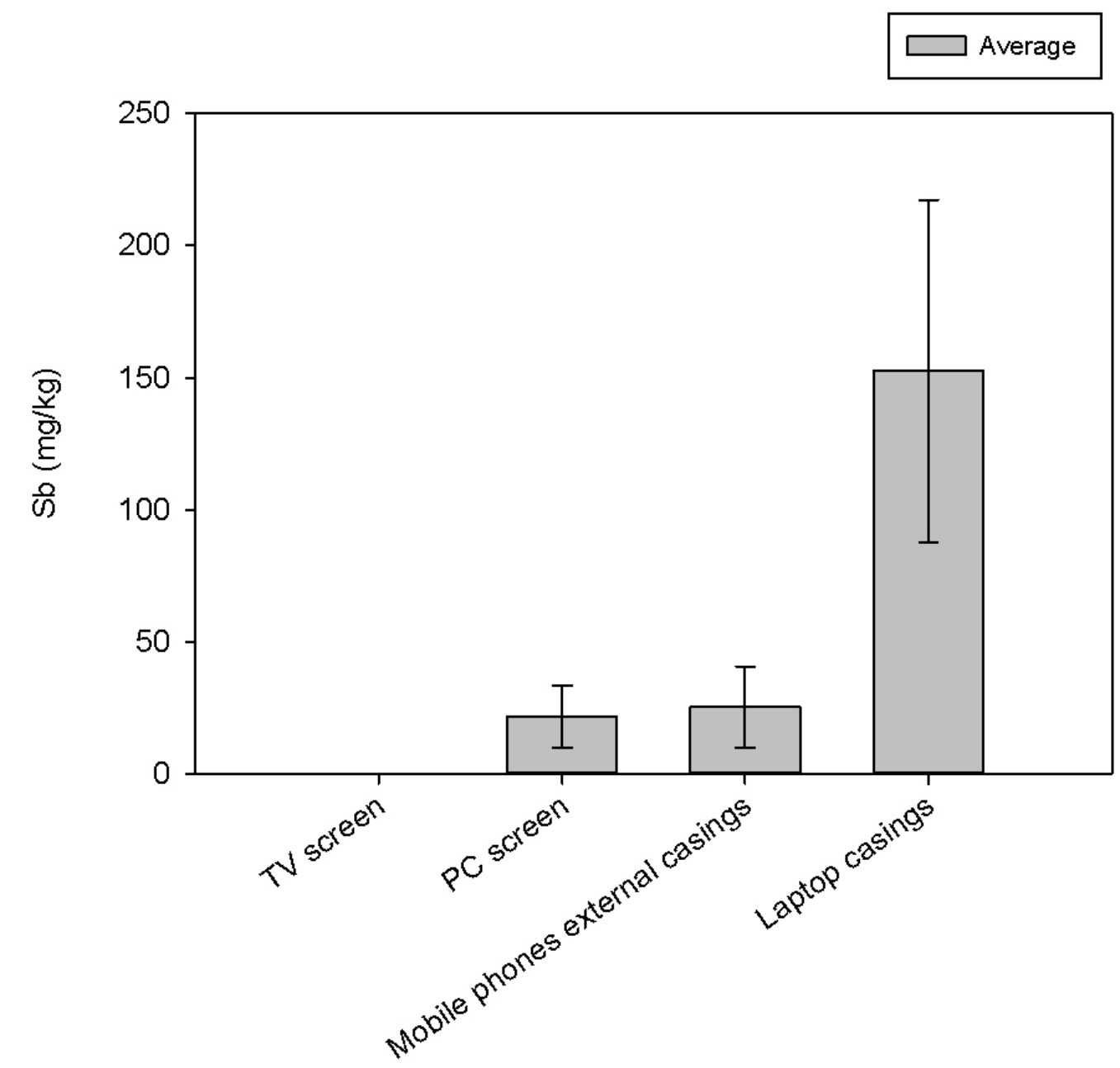

Figure 4. Antimony concentrations in the considered samples (direct measurement by XRF).

\subsubsection{Antimony Extraction from Ashes}

As regulated in the ISO 3451-1 standard [27], the process of ashing was conducted until a constant sample weight was reached, with a maximum duration of $3 \mathrm{~h}$. The sample mass steadiness was reached earlier by the samples derived from the TV screen (Figure 5b) and the PC screen (Figure 5d). The ash content in laptop casings, mobile phone casings, the TV screen and the PC screen was $4.48 \pm 0.10 \%$-wt, $4.62 \pm 1.66 \%$-wt, $0.47 \pm 0.02 \%$-wt and $1.37 \pm 0.02 \%$-wt, respectively. 

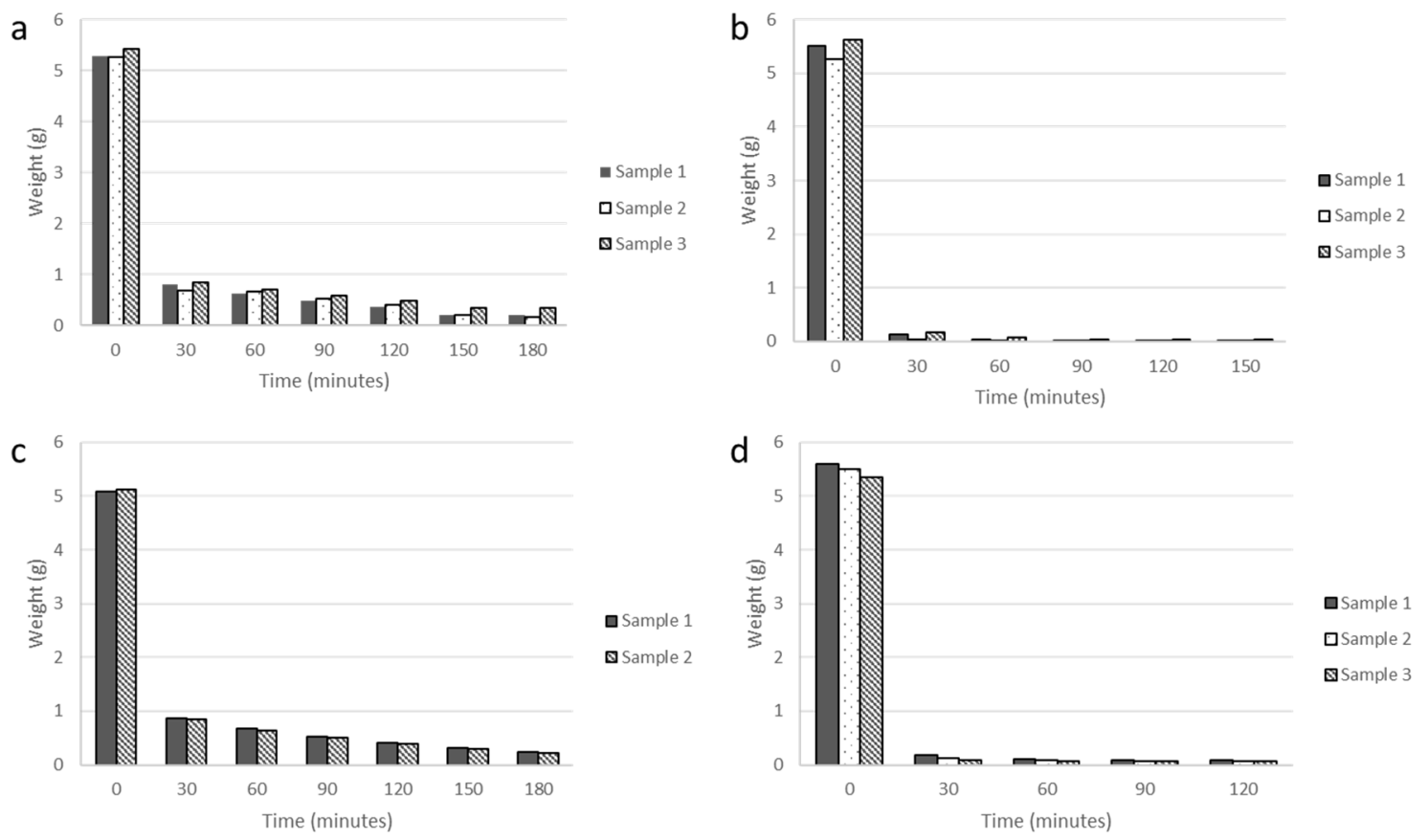

Figure 5. Sample weight change during the ashing process: (a) mobile phones casings, (b) TV screen, (c) laptop casings and (d) PC screen.

\subsubsection{Comparison of Extraction Yields}

Figure 6 shows a comparison of the extraction yields achieved through the examined extraction procedures. Results showed very low concentrations of $\mathrm{Sb}$ extracted from the TV screen $(\leq 8.40 \pm 2.8 \mathrm{mg} / \mathrm{kg})$, with the highest value achieved using $18 \mathrm{M} \mathrm{H}_{2} \mathrm{SO}_{4}$. Since the total $\mathrm{Sb}$ concentration was below the XRF detection limit (14 ppm), extraction yields could not be calculated for the TV screen.

The $\mathrm{Sb}$ extraction yields from the PC screen were as follows: $0.7 \%$ with aqua regia, $19.4 \%$ with $18 \mathrm{M} \mathrm{H}_{2} \mathrm{SO}_{4}$ and $21.5 \%$ with $12 \mathrm{M} \mathrm{HCl}$. On the other hand, $50.1 \%$ of Sb recovery was obtained from the ash form. Extraction at room temperature with $12 \mathrm{M} \mathrm{HCl}$ showed that longer durations obtained higher extraction yields; yields were 10 folds of what was obtained by aqua regia when extraction lasted $2 \mathrm{~h}$ and 20 times higher after $24 \mathrm{~h}$ of incubation.

For mobile phone casings, comparable extraction yields were obtained by aqua regia $(12.6 \pm 10.4 \%)$, $18 \mathrm{M} \mathrm{H}_{2} \mathrm{SO}_{4}(13.3 \pm 15.6 \%)$, and $6 \mathrm{M} \mathrm{HCl},(15.9 \pm 10.5 \%)$. Digestion using $12 \mathrm{M} \mathrm{HCl}$ obtained the highest yield $(21.2 \pm 13.5 \%)$, where material ashing indicated high losses in the fly ash fraction (about $80 \%$ ). Raising the extraction duration from $2 \mathrm{~h}$ to $24 \mathrm{~h}$ at room temperature resulted in an extraction yield increase by $42.7 \%$ (from 5.2 to $7.2 \%$ ), yet the yields were insignificant.

The extraction of $\mathrm{Sb}$ from laptop casings showed elevated $\mathrm{Sb}$ yields, exceeding $100 \%$. Nevertheless, applying the standard deviation values in the assessment provided within-the-limits yields, except for the extraction done using $18 \mathrm{M} \mathrm{H}_{2} \mathrm{SO}_{4}$. Conversely, extraction at room temperature was unable to recover $\mathrm{Sb}$ from the laptop casings. 

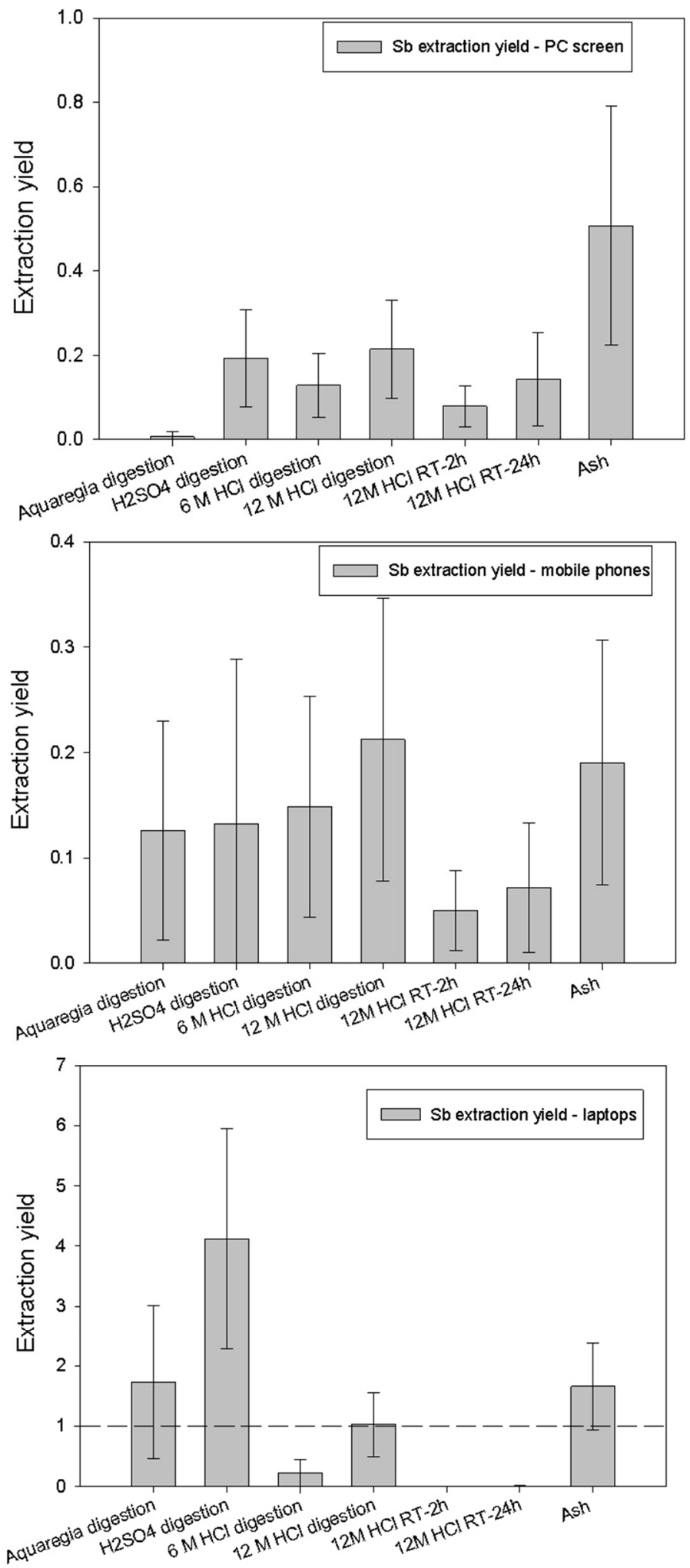

Figure 6. Antimony extraction yields from the considered plastic waste samples. 


\section{Discussion}

This paper analyzes possible methods to address $\mathrm{Sb}$ recovery from plastic waste streams, for the aim of formulating practical approaches for $\mathrm{Sb}$ recycling. Microwave-assisted digestion has often been used to decompose polymers [22,23,33]. Hence, this method was considered for Sb extraction on all the shredded plastic samples. PET samples were only digested with aqua regia, because the extraction procedure immediately proved highly effective, as explained in the following sections.

\subsection{Antimony Recovery from PET}

The assessment of $\mathrm{Sb}$ concentration in PET samples revealed a total content that is in agreement with literature, indicating the effectiveness of XRF in providing the total concentration of $\mathrm{Sb}$ in the samples. Jesus et al., (2016) reported Sb concentration values in PET bottles in the range between 194 and $323 \mathrm{mg} / \mathrm{kg}$, analyzed by means of graphite furnace atomic absorption spectrometry (GF-AAS) [21], whereas Chapa-Martínez et al. (2016) used hydride generation atomic fluorescence spectrometry (HG-AFS) to detect a Sb concentration ranging between 73 and $111 \mathrm{mg} / \mathrm{kg}$ [34]. Takahashi et al., (2008) analyzed 177 PET bottles from China and Japan using X-ray absorption fine structure (XAFS), and $\mathrm{Sb}$ concentrations ranged between 10 and $350 \mathrm{mg} / \mathrm{kg}$ [22]. Westeroff et al., (2008) reported similar concentrations ( $213 \pm 35 \mathrm{mg} / \mathrm{kg})$ from PET bottles [23].

The wide variation in the extraction yield of $\mathrm{Sb}$ from soft drinks bottles could be attributed to the variation in the original concentration in the bottles (they are claimed to be partially containing recycled material). The low $\mathrm{Sb}$ extraction yield from the PET flakes originating from the recycling facility could be explained by the heterogeneous concentration of $\mathrm{Sb}$ in the flakes as a result of handling various types of products and/or by losses during the washing and drying steps of the recycling process. Moreover, the nature of the shredded and washed PET flakes is more brittle in comparison to the flakes of the water bottle purchased from the market, which could have hindered efficient and consistent $\mathrm{Sb}$ extraction. In general, it may be noticed that acidic extraction is a mass transfer process happening through the contact surface between the plastic waste and the extracting solvent; therefore, a higher variation in the experimental results if compared to the direct measurement performed with the XRF spectrometer was expected.

\subsection{Antimony Recovery from E-Waste Plastics}

\subsubsection{Antimony Total Amount in Shredded Samples}

As indicated in Figure 4, $\mathrm{Sb}$ was absent in the plastic fraction of the TV screen, indicating the possibility of using different types of flame-retardants [35].

Generally, e-waste plastic samples exhibited lower Sb concentrations if compared to PET samples (Figure 3), except for the laptop casings. This could be attributed to the production date of these items, where $\mathrm{Sb}$ might have not been extensively used. This was confirmed by the high, yet inhomogeneous flame retardants tracer concentrations [36] (i.e., $\mathrm{Br}+\mathrm{Cl}$ and $\mathrm{P}$ ), showing that other types of flame retardants were present (Table 1).

Table 1. $\mathrm{Br}+\mathrm{Cl}$ and Phosphorous $(\mathrm{P})$ concentration in the analyzed samples.

\begin{tabular}{ccc}
\cline { 2 - 3 } Sample & $\mathbf{B r}+\mathbf{C l}(\mathbf{p p m}) *$ & $\mathbf{P}(\mathbf{p p m}) * *$ \\
\cline { 2 - 3 } TV screen & $417.0 \pm 292.8$ & $2.4 \pm 1.7$ \\
PC screen & $4.9 \pm 0.3$ & $103.1 \pm 2.9$ \\
Mobile phones & $134.8 \pm 0.7$ & $410.9 \pm 8.2$ \\
Laptops & $60.1 \pm 56.0$ & $2755.2 \pm 299.4$ \\
\hline
\end{tabular}

* Analysis done by XRF. ** Analysis done on the ash fraction using ICP-EOS after extraction with aqua regia. 


\subsubsection{Antimony Extraction from Ashes}

Before conducting sample ashing, a pre-ashing step was applied to control the losses which could happen by fast burning (leading to ignition), during which both laptop and mobile phone casings needed longer time under the Bunsen burner to stop generating fumes (see Figure 5). For laptop casings, the fuming was accompanied by liquefaction of the casings, indicating a high concentration of metals [13]. The ash content in laptop casings and mobile phone casings was higher than that in the TV screen and in the PC screen. These results were consistent with the behavior obtained during the pre-ashing step, which predicted higher metallic content in laptop and mobile phone plastic casings. Moreover, and as clearly seen in Figure 5, mass steadiness was reached earlier by the samples derived from the TV screen (Figure 5b) and the PC screen (Figure 5d), indicating their higher organic content and, respectively, their lower metal content in comparison to laptop and mobile phone casings.

\subsubsection{Comparison of Extraction Yields}

The extraction of $\mathrm{Sb}$ from laptop casings presented $\mathrm{Sb}$ yields exceeding $100 \%$, especially for the extraction done using $18 \mathrm{M} \mathrm{H}_{2} \mathrm{SO}_{4}$. These exceeding yields (beyond $100 \%$ total $\mathrm{Sb}$ ) might have happened due to material contamination with laptop inner metals during shredding.

\subsection{Evaluation of Different Extraction Solvents and Conditions}

Different extraction solvents have been tested in this work with the aim of optimizing the extraction of $\mathrm{Sb}$ from e-waste plastic fraction. The samples composition was detected as follows: ABS in TV screen and $\mathrm{PC}$ screen, mobile phone casings were mostly made of $\mathrm{ABS}$, polycarbonate $(\mathrm{PC})$ and a mix of both, and laptops were a mixture of PC/ABS and ABS.

As shown in Figures 6 and 7, the extraction yields by different acidic solvents varied between the samples. This could be accredited to the different polymers present in the samples as well as to the various types of additives and coatings. For instance, extraction using aqua regia showed the least extracted yields of $\mathrm{Sb}$ for both the TV screen and the PC screen (which were entirely composed of $\mathrm{ABS}$ ). When the average extraction values and the standard deviations are included in the evaluation, comparable extraction yields were obtained by $18 \mathrm{M} \mathrm{H}_{2} \mathrm{SO}_{4}, 12 \mathrm{M} \mathrm{HCl}$ and $6 \mathrm{M} \mathrm{HCl}$, indicating that aggressive acids did not improve the extraction from ABS polymer. Furthermore, incubating the samples in $12 \mathrm{M} \mathrm{HCl}$ at room temperature could not achieve Sb extraction from the TV screen, yet incubating the PC screen at room temperature for $24 \mathrm{~h}$ retained concentrations similar to what was obtained by microwave-assisted digestion, proving that $\mathrm{HCl}$ is efficient in impairing $\mathrm{ABS}$. For the mobile phone casings, all acids achieved similar extraction yields, while the lowest yields were obtained by $12 \mathrm{M} \mathrm{HCl}$ at room temperature. Nevertheless, when such low concentrations of $\mathrm{Sb}$ are analyzed in the plastic fraction of e-waste units (the mobile phonecasings in this case), the material would not be considered feasible for $\mathrm{Sb}$ extraction. Laptop casings did not follow the same trend, where digestion using $18 \mathrm{M} \mathrm{H}_{2} \mathrm{SO}_{4}$ provided the highest extraction, followed by aqua regia (about the half of what was extracted by $18 \mathrm{M} \mathrm{H}_{2} \mathrm{SO}_{4}$ ). $12 \mathrm{M} \mathrm{HCl}$ showed significantly higher extraction yields in comparison to $6 \mathrm{M} \mathrm{HCl}$ (factor of increase was around 4.5), when microwave digestion was applied, yet, the extraction at room temperature could not solubilize any $\mathrm{Sb}$. 

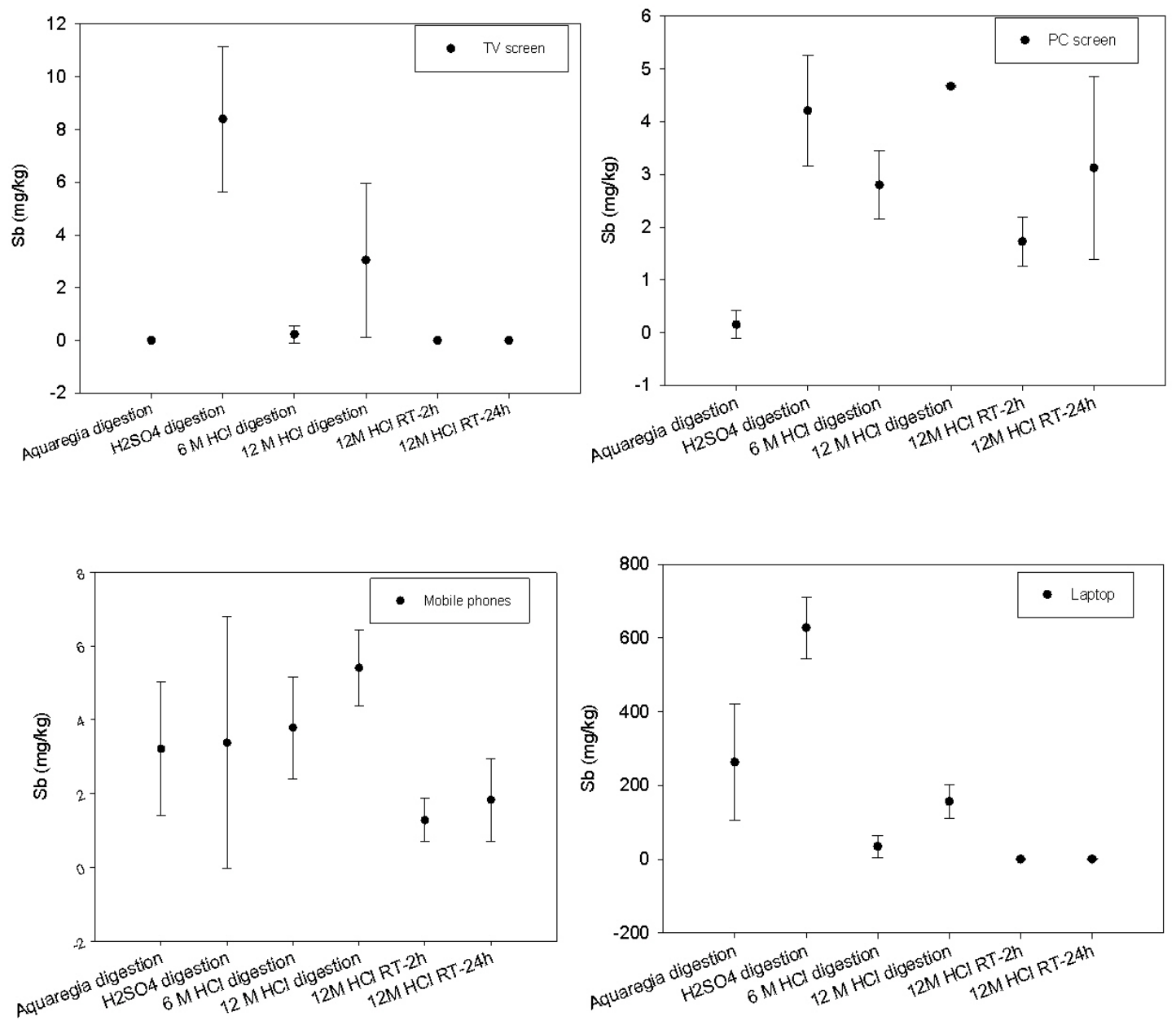

Figure 7. Comparison of the efficiencies of different acids and extraction conditions towards $\mathrm{Sb}$ extraction from e-waste plastic fractions.

\section{Conclusions}

Due to the current supply risk of raw materials, there is an increasing interest in advancing technologies for critical material recovery and recycling $[37,38]$. This study focused on optimizing extraction procedures to recover the critical metal $\mathrm{Sb}$; through assessing different extraction solvents, concentrations and parameters. The antimony content screening performed on the considered samples showed that not all plastic samples derived from e-waste contained significant amounts of $\mathrm{Sb}$, suggesting that other types of flame-retardants were probably used. Direct measurement (through XRF spectroscopy) on the unaltered samples and the analyses of the acidic extracts from ashed samples proved this theory; TV screen contained $417.0 \pm 292.8 \mathrm{mg} / \mathrm{kg} \mathrm{Br}+\mathrm{Cl}, \mathrm{PC}$ screen contained $103.1 \pm 292.8 \mathrm{mg} / \mathrm{kg} \mathrm{Br}+\mathrm{Cl}$, mobile phone external covers contained $410.9 \pm 8.2 \mathrm{mg} / \mathrm{kg}$ $\mathrm{Br}+\mathrm{Cl}$ and $134.8 \pm 8.2 \mathrm{mg} / \mathrm{kg} \mathrm{P}$ and laptopexternal casings contained, in addition to the high $\mathrm{Sb}$ content, high phosphorous content $(2755.2 \pm 299.4 \mathrm{mg} / \mathrm{kg})$.

PET exhibited the highest extraction yields (from 56.6\% to 92.5\%), most likely due to the thin elastic material of which the bottles are composed, which lacks coatings and additives.

For the plastic samples tested from e-waste units, aqua regia was unable to extract $\mathrm{Sb}$ from $\mathrm{ABS}$, while $18 \mathrm{M} \mathrm{H}_{2} \mathrm{SO}_{4}$ and $12 \mathrm{M} \mathrm{HCl}$ were more efficient. For the items composed of ABS/PC and PC, $\mathrm{Sb}$ extraction yields were similar with aqua regia, $18 \mathrm{M} \mathrm{H}_{2} \mathrm{SO}_{4}$ and $12 \mathrm{M} \mathrm{HCl} .6 \mathrm{M} \mathrm{HCl}$ returned lower yields from the laptop casings, yet the yields were intermediate in the mobile phone casings. For extraction at room temperature, only the PC screen and the mobile phone casings returned $\mathrm{Sb}$, and longer durations were more efficient. For future research activities, a wider range of plastic samples 
from various units, polymer types and production dates should be tested, to propose a universal extraction method for $\mathrm{Sb}$ mining from plastic waste streams.

Author Contributions: Conceptualization, A.A., S.F., and K.K.; Methodology, A.A.; Validation, A.A., C.P. and S.F.; Formal Analysis, A.A.; Investigation, A.A and C.P.; Resources, H.S.; Data Curation, A.A., and C.P; Writing-Original Draft Preparation, A.A., C.P., H.S., and S.D.; Writing-Review and Editing, S.F., S.D., and K.K.; Supervision, S.F. and K.K.

Funding: This research did not receive any specific grant from funding agencies in the public, commercial, or not-for-profit sectors.

Acknowledgments: The authors would like to thank Piergiorgio Gazzellone for supporting the experimental activities.

Conflicts of Interest: The authors declare no conflict of interest.

\section{References}

1. Shan, C.; Ma, Z.; Tong, M. Efficient removal of trace antimony(III) through adsorption by hematite modified magnetic nanoparticles. J. Hazard. Mater. 2014, 268, 229-236. [CrossRef] [PubMed]

2. European Commission. Report on Critical Raw Materials and the Circular Economy; European Commission: Brussels, Belgium, 2018.

3. United States Geological Mineral Commodity Summaries 2016. In Antimony. Available online: https: //minerals.usgs.gov/minerals/pubs/commodity/antimony/mcs-2016-antim.pdf (accessed on 28 April 2018).

4. United States Geological Mineral Commodity Summaries 2009. In Antimony. Available online: https: //minerals.usgs.gov/minerals/pubs/commodity/antimony/mcs-2009-antim.pdf (accessed on 28 April 2018).

5. United States Geological Mineral Commodity Summaries 2017. In Antimony. Available online: https: //minerals.usgs.gov/minerals/pubs/commodity/antimony/mcs-2017-antim.pdf (accessed on 28 April 2018).

6. Mathieux, F.; Ardente, F.; Bobba, S.; Nuss, P.; Blengini, G.A.; Dias, P.A.; Blagoeva, D.; de Matos, C.T.; Wittmer, D.; Pavel, C. Critical Raw Materials and the Circular Economy; Publications Office of the European Union: Luxembourg, 2017.

7. Ciacci, L.; Reck, B.K.; Nassar, N.T.; Graedel, T.E. Lost by Design. Environm. Sci. Technol. 2015, 49, 9443-9451. [CrossRef] [PubMed]

8. Barteková, E.; Kemp, R. Critical raw material strategies in different world regions. In The United Nations University-Maastricht Economic and Social Research Institute on Innovation and Technology (UNU-MERIT) Working Papers; Maastricht Economic and Social Research Institute on Innovation and Technology (MERIT): Maastricht, The Netherlands, 2016; Volume 5.

9. Henckens, M.L.C.M.; Driessen, P.P.J.; Worrell, E. How can we adapt to geological scarcity of antimony? Investigation of antimony's substitutability and of other measures to achieve a sustainable use. Resour. Conserv. Recycl. 2016, 108, 54-62. [CrossRef]

10. USGS. Advanced Data Release of the 2016 Annual Tables. Available online: https://minerals.usgs.gov/ minerals/pubs/commodity/antimony/ (accessed on 11 October 2018).

11. Ökvist, L.S.; Hu, X.; Eriksson, J.; Kotnis, J.; Yang, Y.; Yli-Rantala, E.; Bacher, J.; Punkkinen, H.; Retegan, T.; Moya, M.G. Production Technologies of CRM from Secondary Resources: SCRREEN D4. 2; European Union: Brussels, Belgium, 2018.

12. Froehlich, P.; Lorenz, T.; Martin, G.; Brett, B.; Bertau, M. Valuable Metals-Recovery Processes, Current Trends, and Recycling Strategies. Angew. Chem. Int. Ed. 2017, 56, 2544-2580. [CrossRef] [PubMed]

13. Graedel, T.E.; Allwood, J.; Birat, J.-P.; Buchert, M.; Hagelüken, C.; Reck, B.K.; Sibley, S.F.; Sonnemann, G. What do we know about metal recycling rates? J. Ind. Ecol. 2011, 15, 355-366. [CrossRef]

14. van Eygen, E.; de Meester, S.; Tran, H.P.; Dewulf, J. Resource savings by urban mining: The case of desktop and laptop computers in Belgium. Resour., Conserv. Recycl. 2016, 107, 53-64. [CrossRef]

15. Anderson, C.G. The metallurgy of antimony. Chem. Erde-Geochem. 2012, 72, 3-8. [CrossRef]

16. Turner, A.; Filella, M. Field-portable-XRF reveals the ubiquity of antimony in plastic consumer products. Sci. Total Environ. 2017, 584, 982-989. [CrossRef] [PubMed] 
17. Tostar, S.; Stenvall, E.; Boldizar, A.; Foreman, M.R.S.J. Antimony leaching in plastics from waste electrical and electronic equipment (WEEE) with various acids and gamma irradiation. Waste Manag. 2013, 33, 1478-1482. [CrossRef]

18. Schlummer, M.; Gruber, L.; Mäurer, A.; Wolz, G.; Van Eldik, R. Characterisation of polymer fractions from waste electrical and electronic equipment (WEEE) and implications for waste management. Chemosphere 2007, 67, 1866-1876. [CrossRef]

19. Alassali, A.; Fiore, S.; Kuchta, K. Assessment of antimony in plastics from WEEE. In Proceedings of the Crete 2018 6th International Conference on Industrial and Hazardous Waste Management, Chania, Crete, 4-7 September 2018.

20. Dahlbo, H.; Poliakova, V.; Mylläri, V.; Sahimaa, O.; Anderson, R. Recycling potential of post-consumer plastic packaging waste in Finland. Waste Manag. 2018, 71, 52-61. [CrossRef]

21. De Jesus, A.; Dessuy, M.B.; Huber, C.S.; Zmozinski, A.V.; Duarte, Á.T.; Vale, M.G.R.; Andrade, J.B. Determination of antimony in PET containers by direct analysis of solid samples using graphite furnace atomic absorption spectrometry and leaching studies. Microchem. J. 2016, 124, 222-227. [CrossRef]

22. Takahashi, Y.; Sakuma, K.; Itai, T.; Zheng, G.; Mitsunobu, S. Speciation of antimony in PET bottles produced in Japan and China by X-ray absorption fine structure spectroscopy. Environ. Sci. Technol. 2008, 42, 9045-9050. [CrossRef]

23. Westerhoff, P.; Prapaipong, P.; Shock, E.; Hillaireau, A. Antimony leaching from polyethylene terephthalate (PET) plastic used for bottled drinking water. Water Res. 2008, 42, 551-556. [CrossRef]

24. Ibanescu, D.; Cailean, D.; Teodosiu, C.; Fiore, S. Assessment of the waste electrical and electronic equipment management systems profile and sustainability in developed and developing European Union countries. Waste Manag. 2018, 73, 39-53. [CrossRef]

25. Fiore, S.; Ibanescu, D.; Teodosiu, C.; Ronco, A. Improving waste electric and electronic equipment management at full-scale by using material flow analysis and life cycle assessment. Sci. Total Environ. 2019, 659, 928-939. [CrossRef]

26. Park, S.H.; Kim, S.H. Poly(ethylene terephthalate) recycling for high value added textiles. In Fashion and Textiles; Springer: Berlin/Heidelberg, Germany, 2014; Volume 1. [CrossRef]

27. ISO. Plastics: Determination of Ash. Part 1: General Methods. 1997; ISO 3451-1; ISO: Geneva, Switzerland, 1997.

28. Alassali, A.; Abis, M.; Fiore, S.; Kuchta, K. Classification of plastic waste originated from waste electric and electronic equipment based on the concentration of antimony. J. Hazard. Mater. 2019, 120874. [CrossRef]

29. Schweitzer, G.K.; Pesterfield, L.L. The Aqueous Chemistry of the Elements; Oxford University Press: New York, NY, USA, 2010; ISBN 019539335X.

30. Sarkar, S.G.; Dhadke, P.M. Solvent extraction separation of antimony (III) and bismuth (III) with bis (2, 4, 4-trimethylpentyl) monothiophosphinic acid (Cyanex 302). Sep. Purif. Technol. 1999, 15, 131-138. [CrossRef]

31. Telford, K.; Maher, W.; Krikowa, F.; Foster, S. Measurement of total antimony and antimony species in mine contaminated soils by ICPMS and HPLC-ICPMS. J. Environ. Monit. 2008, 10, 136-140. [CrossRef]

32. Michalski, R.; Szopa, S.; Jabłońska, M.; Łyko, A. Application of hyphenated techniques in speciation analysis of arsenic, antimony, and thallium. Sci. World J. 2012, 902464. [CrossRef]

33. Bakircioglu, D.; Kurtulus, Y.B.; Ucar, G. Determination of some traces metal levels in cheese samples packaged in plastic and tin containers by ICP-OES after dry, wet and microwave digestion. Food Chem. Toxicol. 2011, 49, 202-207. [CrossRef]

34. Chapa-Martínez, C.A.; Hinojosa-Reyes, L.; Hernández-Ramírez, A.; Ruiz-Ruiz, E.; Maya-Treviño, L.; Guzmán-Mar, J.L. An evaluation of the migration of antimony from polyethylene terephthalate (PET) plastic used for bottled drinking water. Sci. Total Environ. 2016, 565, 511-518. [CrossRef]

35. Matsukami, H.; Tue, N.M.; Suzuki, G.; Someya, M.; Viet, P.H.; Takahashi, S.; Tanabe, S.; Takigami, H. Flame retardant emission from e-waste recycling operation in northern Vietnam: Environmental occurrence of emerging organophosphorus esters used as alternatives for PBDEs. Sci. Total Environ. 2015, 514, 492-499. [CrossRef]

36. Maris, E.; Botane, P.; Wavrer, P.; Froelich, D. Characterizing plastics originating from WEEE: A case study in France. Miner. Eng. 2015, 76, 28-37. [CrossRef] 
37. Miller, R. Materials Challenges for a Transforming World. Johnson Matthey Technol. Rev. 2017, 61, $126-132$. [CrossRef]

38. Duchin, F.; Levine, S.H. The recovery of products and materials for reuse: The global context of resource management. Resour. Conserv. Recycl. 2019, 145, 422-447. [CrossRef] 